\title{
Adaptations to a Secondary School-Based Citizen Science Project to Engage Students in Monitoring Well Water for Arsenic during the COVID-19 Pandemic
}

\author{
Anna Farrell ${ }^{1}$, Kate Buckman², Sarah R. Hall ${ }^{3}$, Isidora Muñoz ${ }^{3}$, Karen Bieluch², Bill Zoellick ${ }^{4}$, and Jane Disney ${ }^{1}$ \\ ${ }^{1} \mathrm{MDI}$ Biological Laboratory, Salisbury Cove, ME; ${ }^{2}$ Dartmouth College, Hanover, $\mathrm{NH} ;{ }^{3} \mathrm{College}$ of the Atlantic, Bar Harbor, ME; and ${ }^{4} \mathrm{Sch}$ oodic Institute, \\ Winter Harbor, ME
}

Keywords: Citizen science, secondary school, data literacy, community outreach and engagement, Data to Action

Publication Date: July 19, 2021

DOI: https://doi.org/10.15695/jstem/v4i2.05

\begin{abstract}
Secondary schools in Maine and New Hampshire have been involved in a citizen science program called "All About Arsenic" aimed at addressing arsenic contamination of well water, one of the most pressing public health issues in both states. Nearly half of the population of Maine and New Hampshire derive their drinking water from private wells which often have arsenic levels above the EPA limit of $10 \mathrm{ppb}$. Arsenic exposure can cause cancer, adverse cardiovascular effects, and other health problems. Addressing this issue in schools provides context and motivation for students to engage in scientific inquiry and acquire data literacy skills. This project involves students collecting well water samples for arsenic analysis, entering their data into an online citizen science data portal, Anecdata, and using Tuva online software tools to visualize and interpret their data. Students present their data at public meetings to inform community members of their findings with the goal of moving "data to action". The COVID-19 pandemic presented multiple challenges for teachers engaging their students in this citizen science project. We adapted our program and implemented a series of interventions aimed at supporting teachers in their continued efforts to engage their students the "All About Arsenic" project.
\end{abstract}

\section{INTRODUCTION}

MDI Biological Laboratory and Dartmouth College, in collaboration with multiple partners in Maine and New Hampshire, were finishing up year two of "Data to Action: A secondary school-based citizen science project to address arsenic contamination of well water," a National Institute of General Medical Sciences (NIGMS) Science Education Partnership Award (SEPA) project, when the COVID-19 pandemic forced schools to close in March 2020. Our leadership team needed to quickly re-think how our project would culminate for the school year, pivot to online training for teachers to prepare them for the upcoming 2020-2021 school year, and work with teachers to address their varying needs as schools moved to online or a mixture of in-person and online instruction. We retained our overall goal to create a national active learning model of Science, Technology, Engineering and Math (STEM) education that engages students as citizen scientists and provides them with the tools, skills and support to make sense of data so that their project results can inform actions at the local, regional, and even national levels. We adapted our program in a myriad of ways while continuing to focus on data literacy for students. Data literacy is essential for deriving meaning from the results of scientific inquiry; even before the pandemic, grappling with data was challenging and often a barrier to full engagement of students in inquiry-based learning. For our project, which we call "All About Arsenic", maintaining a focus on data literacy is central to realizing the proposed outcomes for the project, which include positive long-term health impacts on the students and their communities.

\section{BACKGROUND}

The rationale for the "All About Arsenic" project is grounded in facts about arsenic contamination of well water in Maine and New Hampshire. Approximately half of the residents in these states depend on private wells for their water at home (New Hampshire Department of Health and Human Services and Nielson et al., 2010), and the number of people who are dependent on well water in rural areas is growing (Johnson et al., 2019) Often groundwater reserves 
in these areas are contaminated with arsenic, in many cases far exceeding the EPA drinking water standard of $10 \mathrm{ppb}$, making exposure to arsenic an important public health issue in both states. Arsenic comes from geogenic sources; exposure may be compounded by proximity to Superfund or other contaminated sites and/or agricultural areas with historical application of arsenical pesticides that can leach arsenic into the groundwater (Hughes et al., 2011). The underlying geology and agricultural history in New England provide context for Maine and New Hampshire students to engage in scientific inquiry and motivation for them to construct knowledge and meaning through the process of discovery. The following information is highly relevant for students involved in the project:

- Maine and New Hampshire have among the highest per capita reliance on private wells for drinking water in the U.S. at $56 \%$ and $40 \%$ respectively.

- This represents approximately 725,000 individuals on private well water in Maine and 536,000 in New Hampshire.

- Private domestic wells are largely unregulated, and the burden is solely on homeowners to test their well water and mitigate any health hazards.

- Commercial or state lab water testing is not commonly utilized by private well users in either Maine or New Hampshire and standard water quality assays in Maine do not test for arsenic. The vast majority of well owners are not aware of the arsenic problem or the level of arsenic in their water.

These facts are especially problematic since numerous studies associate exposure to inorganic arsenic with negative health effects. Long term exposure to water with arsenic can cause numerous severe health problems, including: cancer of the bladder, lung, liver, prostate, and skin; diabetes; heart disease: reproductive and developmental problems; cardiovascular, pulmonary, immunological, neurological, reproductive, and endocrine problems (Naujokas et al., 2013; Carlin et al., 2016). Arsenic exposure of fetuses and babies dramatically increases the risk of cancer and other diseases in adulthood (Farzan et al., 2013). Exposure has been associated with adverse birth outcomes, such as reduced birth weight, in New Hampshire (Shi et al., 2015). Exposure to even low levels of arsenic have been shown to result in lower IQ in children in Maine (Wasserman et al., 2014). Bladder cancer rates in New Hampshire, Maine, and Vermont are $20 \%$ higher than in the US overall (Baris et al., 2016).

This information strikes home for students in Maine and New Hampshire and provides motivation for students participating in our school-based citizen science project to fully engage in the scientific inquiry process. Studies show that when data have immediate relevance for students, they are more likely to expand their scientific inquiry skills (Erwin, 2015) retain what they have learned, and apply it in new settings (Hasni et al., 2016). Data relevance contributes to data literacy and successful inquiry-based learning (Gebre, 2018). Not surprisingly, engaging students in data collection projects that matter to their communities increases their interest and motivation to learn (Ramirez-Andreotta et al., 2015). Motivation is one of several identified success factors for citizen science projects in water quality monitoring (San Llorente Capdevila et al., 2020). Another citizen science project involving undergraduate students in testing drinking water during the pandemic, found the quality of student-collected data can meet quality control standards, even when students are from different academic backgrounds and primarily working in remote environments (D'Alessio et al., 2021).

\section{PROJECT OVERVIEW}

The "All About Arsenic" project has a series of steps that begins with teacher training, partnering teachers with scientists who can assist them with their projects, followed by introduction of students to the arsenic issue and engagement of students as citizen scientists in collecting well water samples for arsenic analysis (Figure 1). The culminating activity

\section{DataLît "All About Arsenic" Project Diagram}

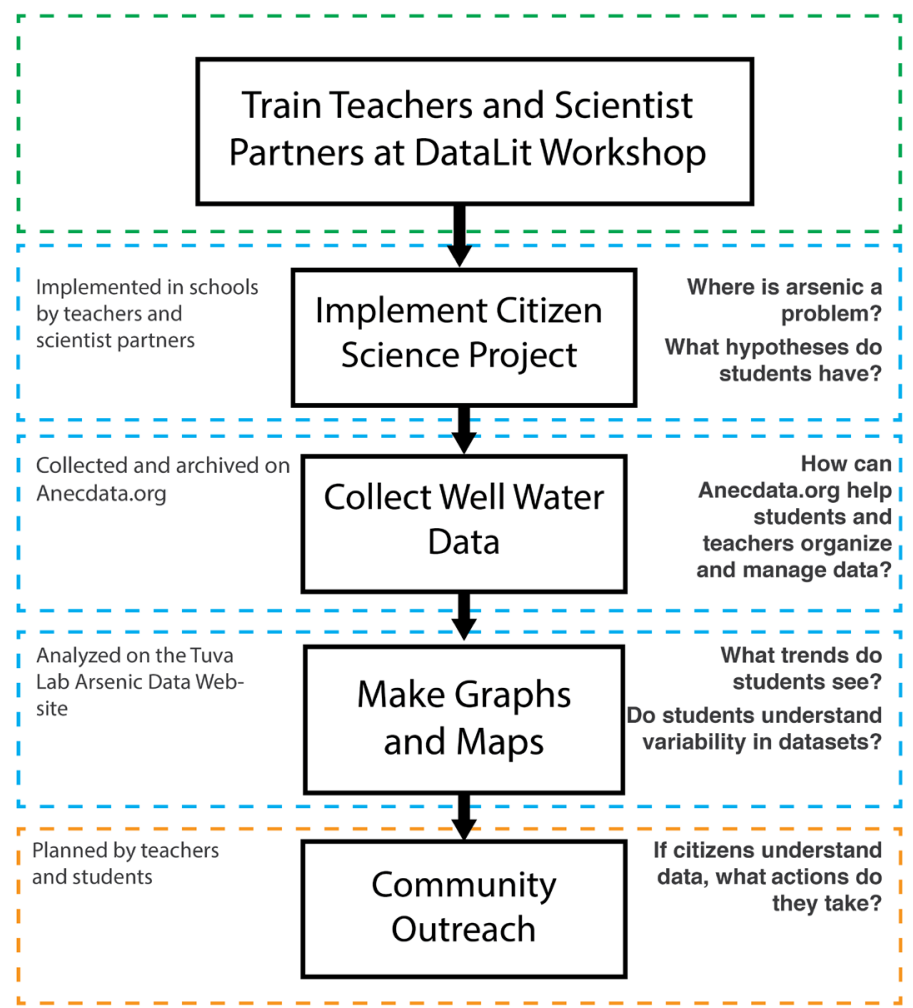

Figure 1. "All About Arsenic" project workflow that is embedded in teacher curriculum. 
for the project involves outreach by teachers and students to their communities, sharing their findings and providing resources for mitigating arsenic in wells. Annually, project coordinators follow up with evaluation in the form of a yearend survey and analysis of required case reports of teacher activities to inform project improvement. Project evaluators conduct annual interviews with teachers to assess progress toward project goals.

Each teacher involved in the project embeds this citizen science initiative into their curriculum in different ways. Some are chemistry teachers who teach about arsenic in well water in the context of learning about elements and the periodic table. Others are biology teachers who engage their students in watershed monitoring. Teachers initiate these projects at different times of year depending on the other aspects of their curriculum.

We were faced with several challenges in the spring of 2020 when schools closed due to the COVID-19 pandemic. At that time, we had 14 schools in Maine and New Hampshire involved in the project. In the face of disruption of regular school life, as teachers and students moved to online teaching and learning, we wondered if the "All About Arsenic" project was going to retain relevance for students. Would the longterm health impacts of arsenic exposure be overshadowed by the immediate potential health impacts of COVID-19? Would teachers be able to coordinate distribution of test kits and collection of well water samples from students given the constraints of remote teaching? Would students be able to grapple with data without in person support from their teachers?

\section{COVID-19 ADAPTATIONS}

Our strategy was first to help teachers finish out the current school year, and second to work with teachers to plan new approaches to the project in the following school year. This required adding new project elements, adapting existing elements, and providing interventions where necessary. In spring 2020, we contacted and interviewed participating teachers who had not yet completed their projects to determine their immediate needs. We offered solutions to help each teacher achieve their end of the school year goals as outlined below. In summer 2020, we moved our annual training for teachers and scientist partners online with a focus on how to initiate projects in the upcoming school year. We created a curriculum development module to help teachers articulate goals and plan activities that could be initiated remotely or in-person. For the 2020-2021 school year, we introduced weekly office hours with teachers so that we could continue to discuss ways to adapt the program as new concerns arose. As part of program evaluation, we conducted focus groups with teachers and scientist partners rather than individual interviews, out of respect for time constraints and because of the perceived need to provide opportunities for teachers and partners to connect. We worked collaboratively with teachers to develop alternatives to public meetings for community outreach. These adaptations, described below, have helped teachers motivate students, keep them engaged in their science education, and facilitated outreach to communities despite the challenges of distanced teaching and learning during a global pandemic.

First Steps when Schools Closed. Our first objective was to contact each of twelve teachers who had not already completed their project for the 2019-2020 school year to have a conversation about where they were in the workflow and what we could do to help them wrap up their projects for the school year. Common themes running throughout these conversations included: reduced access to classroom resources, cancellation of planned activities, concerns about how to accomplish planned and required tasks with reduced time with students, and a potential lack of focus by both students and communities on any non-COVID-19 topics and health concerns. Fortunately, most teachers had already engaged their students in collecting well water and had received their well water test results, with two teachers fully completing the project during the fall 2019 semester. What remained for the others was the required community outreach piece. In the past, most teachers and students hosted in-person community meetings or outreach efforts in their communities. Scheduled outreach activities, for example, with the Pelham, New Hampshire select board or the Hinsdale, New Hampshire school board, were cancelled due to the pandemic. As in-person outreach efforts were now impossible, teachers were challenged to re-think how to engage their students in activities supporting the project's "data to action" goals. We helped teachers in the following ways:

- We provided a list of alternative outreach options that teachers could employ in place of community meetings. These included producing outreach materials to be shared via school newsletters or websites.

- For teachers who did not have time to help students prepare and distribute materials, we prepared materials for them for distribution to communities by teachers and/or students (Figure 2).

- We offered to be the audience for student outreach efforts. We attended two virtual presentations by students on their classroom projects in spring 2020.

With support from the project coordinators, all participating teachers who had not yet completed the project (as outlined in Figure 1) at the switch to remote learning in March 2020, were able to complete their projects with modified community outreach and engagement activities by the end of the 2020 school year. In fact, one teacher even commented 


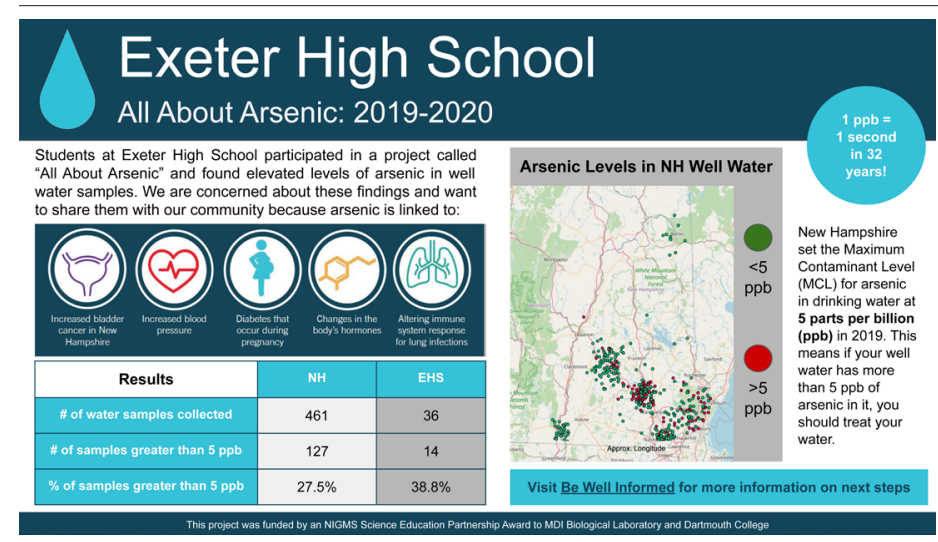

Figure 2. Example of outreach materials we prepared for teachers who needed support with community outreach in 2020 . We used this template to display data relevant to their state and school community. We inserted classroom data into a comparison table and included a state map with approximate locations of tested wells above and below the New Hampshire maximum contaminant level of $5 \mathrm{ppb}$.

that she was "amazed at the projects students came up with" during virtual classrooms, and indicated that the resources provided as part of the "All About Arsenic" project kept her students engaged.

Despite the relative success of the program's immediate response to COVID-19 induced changes in classroom environments and schedules, we knew that larger programmatic shifts were also needed to continue supporting teachers in the participation and completion of project activities throughout the following 2020-2021 school year. Given the uncertainty of what school would look like the next year, we utilized feedback from participating teachers during spring 2020 to focus our efforts on four main areas: preparation for the upcoming year through a transition to online training; maintaining "face-to-face" online connections between teachers, scientist partners, and program coordinators; bolstering accessible lessons to facilitate use of online data exploration tools; and continuing to expand and support alternatives to public meetings for the required community outreach.

Transition to Online Teacher and Scientist Partner Training. Each year, teachers participate in our weeklong workshop, the DataLit Institute. During the institute, we update teachers on the current state of understanding of arsenic impacts on human health, share the findings of collaborating researchers who are studying well water and arsenic, introduce new resources we have developed, and provide opportunities to learn about hands-on activities for classrooms. The DataLit Institute also provides opportunities for teachers to meet with each other, talk about curriculum, exchange ideas, and build collaborations, including with their scientist partners. Transitioning these activities to an online environment presented challenges that we were able to address by drawing on the expertise of multiple project partners, re-thinking priorities, developing tools to guide teachers through activities, providing time for teachers to work in small breakout groups, and working with teachers to plan for varying remote teaching and learning scenarios in the upcoming school year. A major change from previous iterations of the DataLit Institute was the incorporation of dedicated time to design and discuss their curriculum plans (Figure 3). The 2020 DataLit Institute had sixteen teacher participants, four of whom were new to the program. They were joined by twelve scientist partners, five of whom were also new to the program. Even in a pandemic year, we had new interest in the project with additional teachers and scientist partners willing to get involved.

One of the tools that we implemented was an individual curriculum development planning process in the form of an Excel workbook. Our tool was adapted from one used in training sessions for Entering Research, a customizable curriculum for undergraduate and graduate research training (Branchaw et al, 2020). This individual curriculum development planning process uses an Understanding by Design (UbD) framework to guide development of curricula (Wiggins and McTighe, 2005). The UbD framework is particularly relevant for developing citizen science initiatives in classrooms because it has the aim of focusing curriculum and teaching on the development of student understanding and ability to apply what they learn in new contexts. In this framework, the learning objectives are defined first, then learning activities are selected to support achievement of the learning objectives, and finally, assessment strategies are defined to measure progress. The workbook that we designed consisted of multiple worksheets, each dedicated to a different step in the curriculum development process.

Step 1: Identification and Prioritization of Student Learning Objectives

Step 2: Implementation Planning: Identification of Opportunities and Challenges

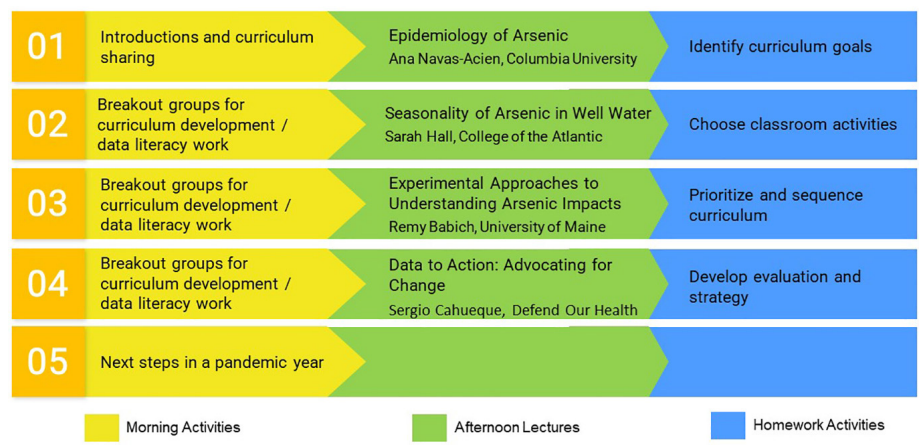

Figure 3. The 2020 DataLit Institute was held online in a virtual format. The 5-day schedule facilitated whole and small group work in breakout sessions. Lectures by experts provided opportunity for in depth content for teachers. Teachers built out their curriculum in evening homework assignments that were discussed in breakout groups the following day. 
Step 3: Learning Activities Aligned with Prioritized Student Learning Objectives

Step 4: Assessment Tools Aligned with Prioritized Student Learning Objectives

Step 5: Synthesis Grid for Steps 1-4

Step 6: Implementation Timeline (Schedule)

Step 7: Case Study Development

The steps were combined in a synthesis grid and teachers then put their project activities on a timeline. Written case study reports are a requirement for teachers at the culmination of each school year. We added a worksheet with a case study template for teachers to begin planning their case studies in advance and to support their case study development during the school year. Teachers were asked to develop one step in their individual curriculum plan each night during the DataLit Institute. The workbooks were kept in a shared folder on a Google Drive to enable viewing by all participants and DataLit Institute facilitators.

In the end of the school year survey, when asked which adaptations of the program were helpful, one teacher reported: "This school year was extremely busy so having a curriculum already made was so helpful! I would constantly look back to see what I could incorporate and when to do it."

One additional outcome following discussion during the DataLit Institute was teachers' increased commitment to collect samples during the fall, even if their students would not be working with the data until the spring term. Of the sixteen participating schools, most submitted their samples in the fall, and all had collected and submitted water samples for analysis by the end of the 2020-2021 school year.

\section{Introduction of Thematic Office Hours to Revisit Topics} and Reinforce Learning. Feedback during and following the online DataLit Institute indicated an overwhelming positive response to the breakout groups allowing teachers and their scientist partners to talk to each other and share what has worked and did not work well in their respective classrooms. In the post-workshop survey, new teachers reported that working with experienced teachers who had participated in the project for multiple years was helpful. To maintain and promote this positive interaction in an online format, we instituted "office hours" hosted via Zoom. Over the course of the 2020-2021 school year, we hosted 12 sessions with themes ranging from how to use new/updated online resources to general discussions of expanded outreach options (Figure 4). Office hours featured a short presentation or demonstration by program coordinators, teachers, or scientist partners followed by time for participants to engage in discussion about the focus topic, or bring up challenges or successes they were currently experiencing in the project and receive real time feedback and support from the group.

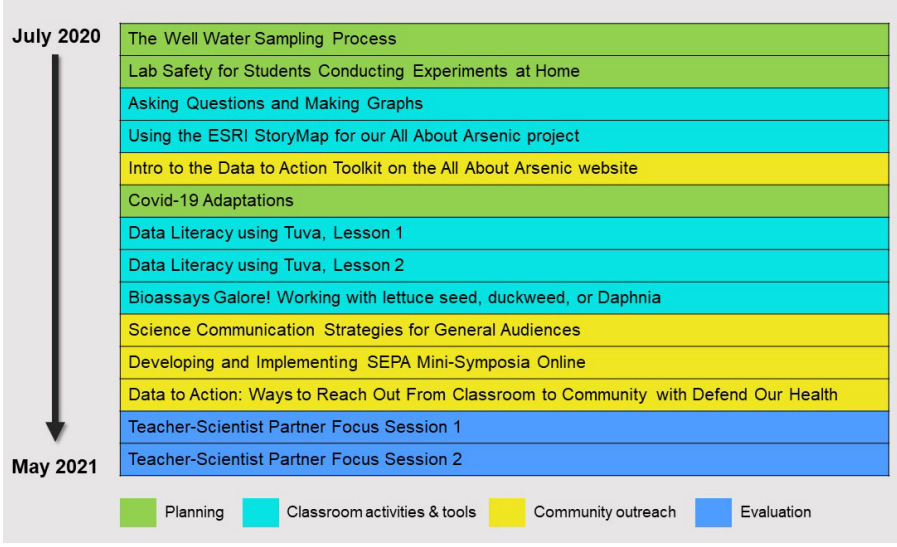

Figure 4. Office hour topics color coded by theme.

These office hours also allowed us to remotely introduce new project partners and provide demonstrations of some of the tools (e.g. Data Literacy Modules, Civic Action Toolkit) discussed further below.

One challenge of the office hour format was that not all teachers could attend all sessions. While recordings were accessible after the fact, the valued virtual interaction was lost. Nonetheless, of fourteen teachers who participated in our annual end-of-school year survey in April 2021, over half reported that the office hour sessions were somewhat to very helpful. From this, we conclude that these sessions are worth continuing post-pandemic to maintain connections between project coordinators, teachers, and scientist partners beyond the annual DataLit Institute.

In addition, our external evaluators took advantage of the dedicated time for office hours to host two end-of-school year focus sessions, to garner feedback for evaluation and grant reporting. The end-of-year focus sessions with the teachers explored the following questions:

1. What project-related activities did you use in your curriculum to help students strengthen data literacy? What were your greatest frustrations and successes?

2. What project-related activities did you use to improve public health awareness and action about arsenic in drinking water? What were your greatest frustrations and successes?

3. What modifications did you have to make to your project-related activities due to the pandemic? How did it turn out? What lessons were learned? What things will you continue to do moving forward?

4. What are your reflections on the how the "All About Arsenic" project fit into your classroom curriculum this year?

What emerged in discussion of these questions during the focus sessions was the frustration of teachers trying to implement this project, as well as anything else during the pan- 
demic. As one teacher put it, "For me, everything was hard this year. I only see my students in person once a week." Another said, "I am literally this week catching my breath from this entire year. Since the beginning of the year, it has just been really difficult, trying to figure out all the technology of how to even survive as a teacher."

Almost all the teachers spoke about the ways that the disruption and uncertainty caused by the pandemic made it difficult to manage the scheduling required to do the analysis of the well water data once it was available. This was even more challenging in the many schools that decided to compress what had been full year classes into a single semester. "During the first semester, my chemistry and my outdoor science students sampled their wells, but we got our results back just before Christmas. And then we went remote right after Christmas and then the semester was over."

For teachers with many students learning remotely, the logistics of getting sample collection containers out to households, and getting samples back was difficult. "The paperwork on the samples was problematic. Last year, we took a day for students to enter all their sample information [into the citizen science website, Anecdata.org] at school. This time it was a nightmare because there were students who had missed [entering] information [from home]."

Despite these types of challenges, teachers reported that the program was essential to finding success in their classrooms during this pandemic year. One teacher stated: "Students have gone through the process of writing a method and doing some research.... So, you know, it's valuable." Another said, "The Arsenic project is great, and it's looped me into my data, but I'm trying to get it to fit in with everything else. And what was fascinating this year was I didn't give a final exam for this course. What I did was I took all the stuff that we've been doing through the year's data analysis and combined it into a climate activity that they had to do, but I threw in the Tuva [data literacy software] with it. And it was a lot of [information and skills] they had learned from the arsenic data analysis that we were using with other [units of study]. So, I was really pleased with how this project had tied into my whole curriculum that way."

A few teachers decided to focus even more on the project this year than in the past. "In the middle school curriculum, it fits really nicely. I've actually spent more time this year than I have in the past with this. I gave up another unit to do this project because we're doing an introduction to chemistry. We're talking about periodic tables, so the kids did a lot of research on that. And this year I just had them research the elements that we'd be finding in our well water results. I liked it a lot. It worked out for me as a middle school teacher."

Development of Data Literacy Modules. An integral aspect of the All About Arsenic project is the use of Tuva, an online graphing and data literacy software, to explore the growing well water data set, learn how to make graphs, examine relationships, and communicate findings. When schools switched to distance learning in spring 2020, one teacher expressed that they could not utilize this tool with their students without being able to work with them in-person. Teachers who had used it previously said they felt it was extremely beneficial for their students, yet post-workshop survey results from the summer 2020 DataLit Institute indicated that there was not enough time to explore all the various capabilities of Tuva within the format of the online workshop.

Therefore, later in the summer of 2020, program coordinators worked with a data literacy consultant from Tuva and a participating middle school teacher to develop new Data Literacy Modules to help provide a scaffold for learning and support teachers in helping their students develop data literacy skills. The effect of this added support was evident in teacher's descriptions of their data literacy activities during the evaluation focus sessions described above. Although in previous years we have noted that teacher's lack of familiarity and comfort in working with and teaching about data is sometimes an impediment to their helping students developing data literacy skills, we noted that there were changes in teachers who have been with the program for more than one year. This is consistent with research studies that suggest that the process of acquiring basic data literacy pedagogical content knowledge extends over a number of years (Ben-Zvi and Garfield, 2004; Zieffler and Fry, 2015).

To enable teachers and students in using Tuva in both classroom and distance learning settings, we designed five Data Literacy Modules, online lessons with instructional videos all centered around existing data sets in Tuva. These lessons were designed to help students explore the basic functionality of Tuva, ask meaningful questions, choose graphs that help them answer their questions, and deal with data variability with some basic statistical analyses:

Lesson 1: Asking questions and choosing graph types

Lesson 2: Simplifying data to focus on a specific question

\section{Lesson 3: Making comparisons between datasets}

Lesson 4: Exploring ways to visualize data to tell data supported stories

Lesson 5: How sure can you be? Using basic statistics to support conclusions

Over 70\% (13/14) teachers who responded to the endof-year survey found the data literacy modules and videos somewhat to very helpful. Written comments from teachers indicated that Tuva was an extremely helpful platform during distance learning, but did not elucidate the extent to which teachers integrated these new data modules into their curric- 
ula. When asked what data literacy tools and supports were most effective, teachers offered the following comments:

- "The website and archives of past materials are very helpful. Also, Tuva is great."

- "The instruction videos and modules."

- "The students have loved using Tuva in terms of creating their own graphs for our area."

- "Tuva and the 'All About Arsenic' web site have been most helpful."

Introduction of StoryMap as a Curriculum and Outreach

Support. The ArcGIS StoryMap is a new, interactive online tool that has multiple applications in teacher training (Lee, 2020), education (Dickinson and Telford, 2020), and public outreach (Malkowski and Klenke 2020). As GIS technology has become a huge part of the daily experience of people using smart phones, navigation software, and viewing satellite imagery through software such as Google Earth, it seemed like both a timely and accessible way to build spatial data visualization and interpretation skill-building into curricular resources for middle school, high school, and college level students. StoryMaps are designed to be self-guided, providing a way for users to interact with spatial data on their own, so it can serve as a homework assignment, in class activity, or even be featured as part of a lecture. We envisioned our teachers using it as both a resource for themselves to build their own content knowledge and spatial skills and also to use as a tool to enhance their curricular offerings. In addition, there are emerging examples of StoryMaps being used as public engagement tools where they can serve as online digital storytelling platforms centered on sharing datasets in a narrative framework (Howland and Liss, 2020). Therefore, we saw development of a StoryMap for the "All About Arsenic" project as a way to support teacher and student efforts to share information with their communities.

We had developed the first iteration of the "All About Arsenic" StoryMap before the pandemic started. It featured only a map with many different interactive layers and some information about the geologic history of the Mount Desert Island, ME region. We focused on this first because there was very little geoscience built into the "All About Arsenic" project at the start, as the focus was mainly on raising awareness of arsenic as a public health issue and building data literacy. GIS techniques that enable layering of different spatial datasets enables practice with spatial and temporal data visualization and literacy. So, through this initial effort, we hoped to both provide geoscience content connected to the broader "All About Arsenic" project, but also to provide a platform for additional data literacy practice.

The initial feedback from teachers (first in breakout groups during the 2020 DataLit Institute and then in the fol- low-up office hours during the school year) indicated their interest in our:

1. building out the StoryMap to include data layers and site-based content from Maine and New Hampshire

2. adding more content information beyond the geologic history - to include hydrology and policy information as well.

3. including information for how to use the StoryMap and how it is connected to the "All About Arsenic" project.

We addressed teacher feedback by expanding the StoryMap content and functionality during the 2020-2021 school year. We also made the StoryMap easily accessible on the project website ("All About Arsenic", 2021). We expanded the StoryMap to include a "Generalized Geology of New England" section to address \#1 above, and are currently working to expand the New Hampshire-specific material. We added hydrology and policy content that continues to be updated to address \#2. The hydrology content will connect to a dataset featuring regional USGS streamgage and groundwater well data for teachers to use with their students to discuss the water cycle, seasonality of groundwater changes, and other related topics. The policy content will provide a historical timeline connected to our new "Data to Action" toolkit (described below), enabling teachers to engage their students in civic action around the topic of drinking water quality. To address \#3, we added a welcome page that features some information about the history of the "All About Arsenic" project and provided links to the project website.

We decided to make specific examples of how the teachers could use the spatial data and other information on the StoryMap with their students. We have begun to make example lessons that are ready to go. Teachers can assign them as homework or use them in their classroom as a group activity or discussion. So far, we have produced two examples: Example 1 focuses on the spatial distribution of contaminants in drinking water and testing behavior; example 2 focuses on the connection between geologic and human processes and drinking water quality. In both examples, students are asked questions and then guided through how to use the maps and other visualizations (graphs, figures, etc.) to generate ideas or answers to the questions. Both examples end with synthesizing questions and opportunities for further study.

We plan to add at least two more example activities, one on the hydrology and one on the policy content. One issue is that some of the maps take a while to load on different browsers. Given the different connectivity/accessibility of the students, we are working with a GIS technician to simplify the maps dataset to enable faster loading.

Over 50\% (8/14) teachers who responded to the end-ofyear survey found the StoryMap somewhat to very helpful. However, 36\% (5/14) responded "not applicable", indicating 
they did not use the StoryMap in their curriculum. We anticipate that new features, improved map loading speed, and associated curriculum will make the StoryMap more useful and widely adopted as a project support tool.

Community Outreach Adaptations. During the pandemic, one of the largest challenges for teachers was how to engage their students in the required community outreach. Therefore, project coordinators expanded their focus this year from strengthening teacher data literacy skills to supporting other aspects of their curriculum, such as science communication and translating "data to action". Community outreach adaptations took multiple forms and encouraged engagement and communication not just with students' local geographic community, but with the broader "All About Arsenic" community, and aimed to facilitate the translation of outreach and communication skills beyond arsenic. Our hope is that students will be able to utilize aspects of the data interpretation, communication, presentation, and civic action learned during community outreach regarding well water contamination beyond the science classroom. For example, the "Data to Action" toolkit can be utilized for any topic a student is passionate about, regardless of whether it involves environmental science or public health. Similarly, the ability to discuss the interpretation of patterns and numbers is applicable outside of a school assignment.

Mini-symposia. At the 2020 DataLit Institute, teachers discussed the idea of sharing information between schools. Because students were meeting virtually with their teachers, the opportunity for multiple schools to meet and exchange information was possible. We supported teachers and students in the development of mini-symposia between schools to encourage information exchange and data dissemination. A science communication graduate student from the University of Maine hosted two office hour sessions on developing online symposia and communicating with general audiences to help teachers and students prepare. Two mini-symposia took place during the 2020-2021 school year, one between Bow and Kearsarge high schools in New Hampshire and another between Conners Emerson and Mt. Desert Elementary middle schools in Maine. The end-of-year survey was implemented before these events took place, but teachers reported that planning for the mini-symposia by engaging in conversations about science communication for general audiences was helpful.

“Data to Action" Toolkit. Also, at the 2020 DataLit Institute, teachers indicated an interest in engaging their students in advocacy work as a way to disseminate information about their project and effect change in their communities. After the training, we conducted a survey to assess teacher interest in development of a toolkit, how they would want to im- plement the toolkit (on their own or with in-classroom support), and when they would like to get started. Ten teachers responded to the survey, eight indicated interest in pursuing this mode of outreach with their students, and we followed up with each of them during the school year. We worked with a community group focused on removing toxic contaminants from the environment called Defend Our Health and a College of the Atlantic undergraduate to develop a "Data to Action" toolkit on our "All About Arsenic" website (https://www.allaboutarsenic.org/data-to-action-toolkit/). It provides resources, templates, and links to information on:

- How to talk about science with anyone

- Who are your legislators?

- How to know what to say when you write to your legislators

- How to know what to say when you call your legislators

- How to submit an Op-Ed

- How to write a letter to the editor

- How to get organized to take action

- How to take action

Teachers and their scientist partners were introduced to the toolkit in one of the scheduled office hour sessions. Then later, teachers and scientist partners learned about proposed legislation in Maine in a follow-up office hour session. L.D. 1570, "An Act To Protect Drinking Water for Maine Residents", is a bill that requires landlords to test well water for arsenic and other contaminants and disclose the results to prospective and current tenants, requires that the state provide free well water testing to low-income families, and lowers the maximum contaminant level (MCL) for arsenic in drinking water.

Teachers were offered the opportunity for virtual classroom visits with a representative of Defend Our Health and a College of the Atlantic undergraduate to learn the history of arsenic contamination of well water and efforts to mitigate effects on public health (Figure 5), principles of advocacy and direct action organizing, and to gain more information about L.D. 1570. Three teachers invited these representatives to visit their classrooms; during the visit, students learned the difference between advocating for something on behalf of others, like legislation, and direct action organizing, which, in terms of this project, would involve getting others to test their wells for arsenic or to advocate for legislation. These classroom sessions included an activity where students were asked to write down three to five main talking points that they would like to share with other people who don't know anything about arsenic. These three teachers found the classroom visits helpful. In follow-up emails, they expressed appreciation, praised the organization of the presentation, and 


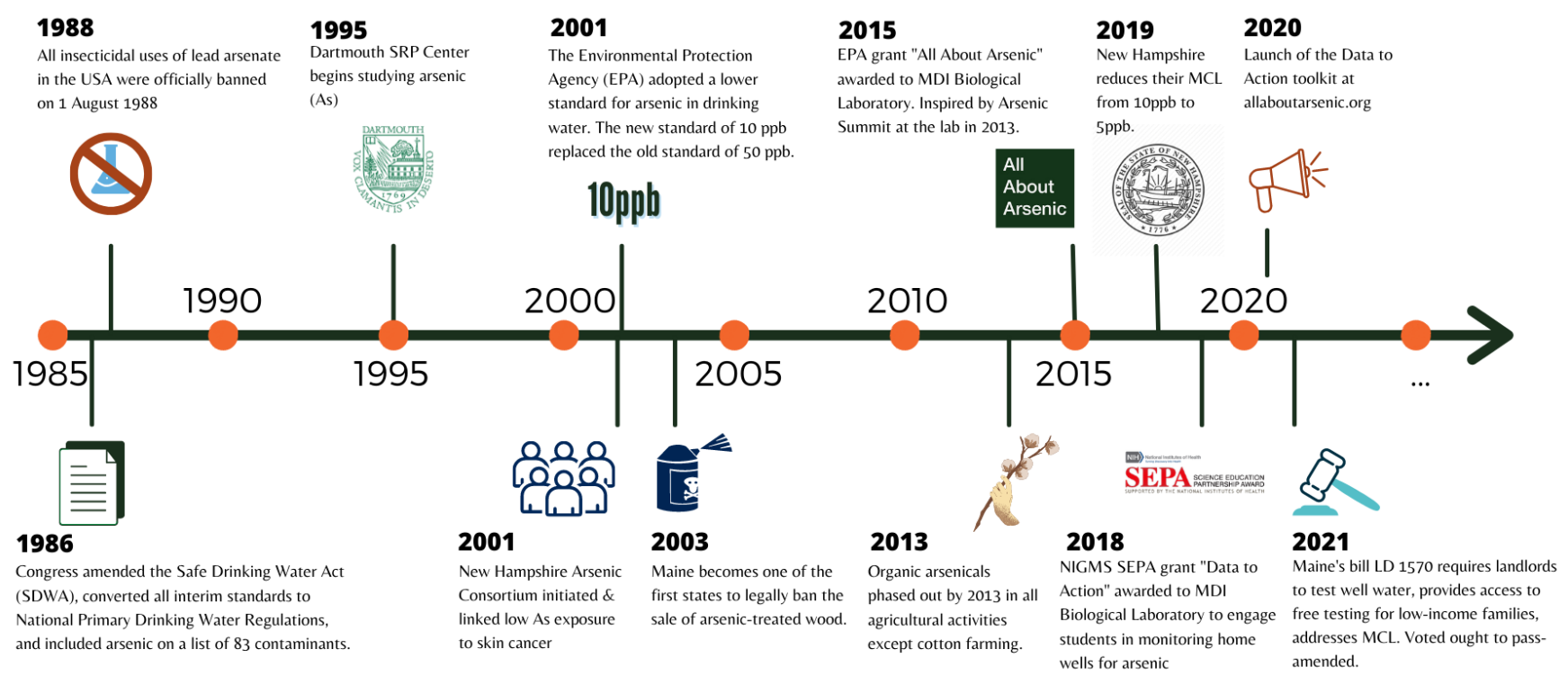

Figure 5. Timeline of arsenic related events in both Maine and New Hampshire. Creation of a "Data to Action" toolkit to support teacher and student work in advocacy and direct action in response to proposed legislation in Maine were key project events during the COVID-19 pandemic.

reported that students were excited to support L.D. 1570 based on their own data.

Five teachers provided opportunity for their students to share their insights and opinions with legislators. Two schools sent written testimony to the Maine Health and Human Services Committee that was considering the bill; students from another school made a recording to share with committee members and legislators; and other teachers provided their students with opportunities to write letters to the editor of their local newspapers. One teacher met virtually with the local deputy code enforcement officer to discuss student participation in a town-wide effort to get all wells tested and is planning to engage students in direct action in fall 2021.

Nearly all (13/14) teachers responding to the end of year survey found the introduction to advocacy principles and the "Data to Action" toolkit on the "All About Arsenic" website to be somewhat to very helpful in engaging their students in these civic action types of outreach activities.

Scientist Partner Involvement. During the pandemic, relationships between scientist partners and teachers took new forms. Unlike prior years when scientist partners and in some cases, their undergraduate students could visit the teacher's classroom to give a talk, support data analysis, have their undergraduates share their experiences and scientific projects, or support the planning process for outreach such as the community meeting, those types of in-person interactions were not possible in the 2020-2021 school year. In addition, both scientist partners and teachers were stretched for time to plan ways to adapt or modify outreach efforts. However, some unique opportunities presented themselves and teachers and scientist partners took advantage of these opportunities to share their findings with wider audiences.

Two teacher-scientist partner teams (Kearsarge High School and Colby Sawyer College in New Hampshire and Waterville High School and University of Maine at Augusta) co-presented their projects in a special session on arsenic in well water at the Maine Sustainability and Water Conference (MSWC) in March 2021. Preparation for the conference provided an important focus for their collaboration this year and sparked conversation among one pair where there previously had not been communication. We think of the presentations as boundary objects, or objects that sit at the boundary of two or more unique groups and which the groups collaboratively develop (Cash et al., 2003). Boundary objects facilitate knowledge sharing and improve communication (McGreavy et al., 2013). The MSWC presentations as boundary objects helped support and strengthen teacher-scientist partner team collaborations, partly by providing those groups with a shared purpose and partly by encouraging communication that strengthened their shared understanding of their work.

In another example, a scientist partner at Keene State Col- 
lege invited students from her partner school to participate in a panel discussion at the Keene State Academic Excellence conference. Students from Bow High School presented work they had done on bioassays to an audience that included the Keene State College campus community and invited friends and family.

Other Outreach Adaptations. In previous years, poster sessions at science fairs and public meetings were the primary community outreach activities, all aimed at sharing well water data and increasing awareness of arsenic as a public health issue. The pandemic was one factor that pushed some teachers toward new ways of thinking about how to translate "data to action." Some of the additional outreach activities by teachers and students during the COVID-19 pandemic include:

- Collecting additional samples from well owners in their community as an outreach component of their classroom curriculum.

- Contacting a local pediatrician to share information about the neurological impact on children exposed to arsenic in well water, providing test kits for distribution by the pediatrician to new parents and producing outreach materials to share with parents when well water test results came in.

- Analyzing multiple years of data with students to look at trends and reporting the information to their Board of Selectmen.

\section{OVERALL OUTCOMES}

Despite the pandemic, sixteen teachers worked with scientist-partners and engaged a total of 948 students in the "All About Arsenic" citizen science project during the 20202021 school year. They were able to collect a total of 518 water samples bringing the total dataset for the SEPA project to 1,893 samples (Figure 6). Schools were able to collect similar numbers of samples during the pandemic as they did in previous years. In Maine, there were 34 households with well water exceeding $5 \mathrm{ppb}$ arsenic and in New Hampshire, there were 48 households with well water exceeding $5 \mathrm{ppb}$ arsenic. All of the well owners were notified and provided with resources to address the elevated levels of arsenic in their well water. Because teachers persisted and students were engaged, a total of 82 families may be spared the health consequences of long term exposure to arsenic in their well water.

At the same time, teachers and students had opportunities to engage more deeply with the well water dataset, given the added supports for data exploration implemented this school year. Teachers and students had opportunities to communi-

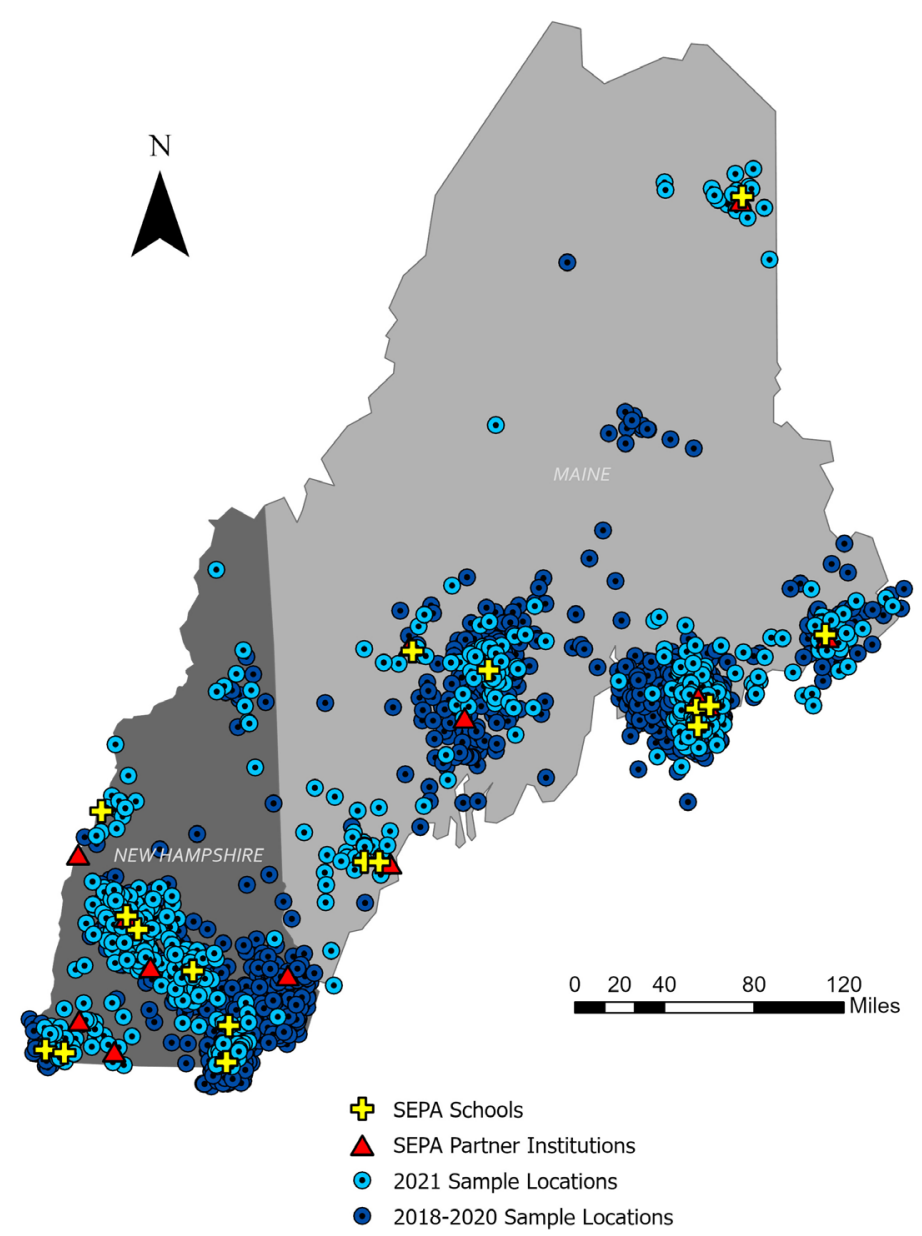

Figure 6. Map of well water sample locations demonstrates the scope of the sampling effort by schools during the COVID-19 pandemic.

cate with broad audiences even though they could not be together with community members in person. Relationships between teachers and scientist partners were deepened by combining their training at the DataLit Institute, introducing office hours for everyone, and providing unique opportunities to work together (such as the Maine Water and Sustainability Conference).

Most, if not all, of the COVID-19 adaptations and interventions were project improvements and will be maintained after the pandemic is over. Now that we are all adept at using conferencing software, we will meet more often outside of the DataLit Institute. Office hours will become a consistent and integral part of the project, allowing teachers and scientist partners from across two states to regularly meet and exchange information and learn new things together and from each other.

Evaluative Survey Results. The year-end evaluation survey with questions specific to COVID-19 adaptations of the "All About Arsenic" project helped to provide an overall picture of what strategies most helped teachers during the 2020-2021 school year. When asked explicitly 


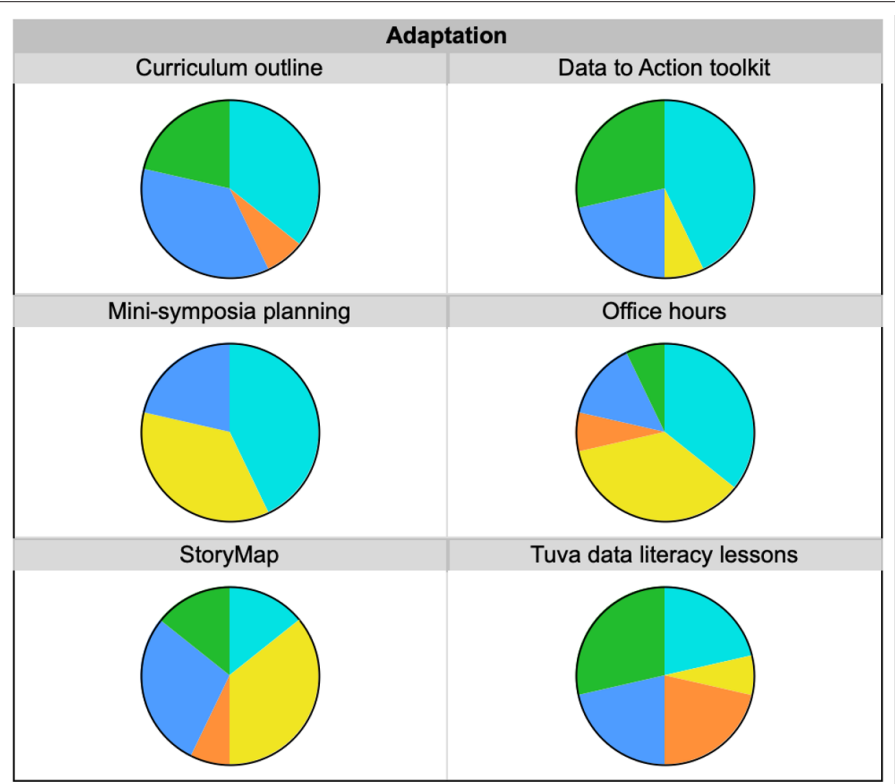

very helpful

helpful

somewhat helpful

not helpful N/A

Figure 7. Proportion of teachers responding to the question "How helpful were the following adaptations or interventions for the "All About Arsenic" program?" There were 14 respondents in total.

how helpful each of the COVID-19 adaptations were, most of the responses were positive (Figure 7). The adaptations that seemed the most helpful to the most teachers include the curriculum development process created for the DataLit Institute in 2020, the "Data to Action" toolkit that helped teachers involve their students in civic action, the addition of thematic office hours during the school year, and the new data literacy lessons for scaffolding student learning. These are all strategies that we will continue to implement and tools we will continue to use post-pandemic. Where large numbers of teachers indicated "not applicable", such as office hours and mini-symposia planning, for example, we see the need to provide flexible and/or multiple offerings to accommodate teacher schedules and interests. In terms of the StoryMap, we see a need for more specific instruction on how to use the StoryMap and integrate its capabilities and resources into classroom curricula, a process we have already begun to implement as discussed above.

Another series of questions on the end of year survey dealt with teacher impressions of student aspirations and attitudes toward science (Figure 8). They were asked to assess the degree to which they agreed with six different statements on a Likert scale ranging from strongly agree to strongly disagree on a 5 point scale. We asked the same series of questions toward the end of the 2019-2020 school year as we did at the end of the 2020-2021 school year. There was a slight drop in the weighted average across questions, except in response to the statement about students disliking science. That response had an increased weighted average, which is consistent with the other responses in that it indicates that students' interest in science decreased during the pandemic.

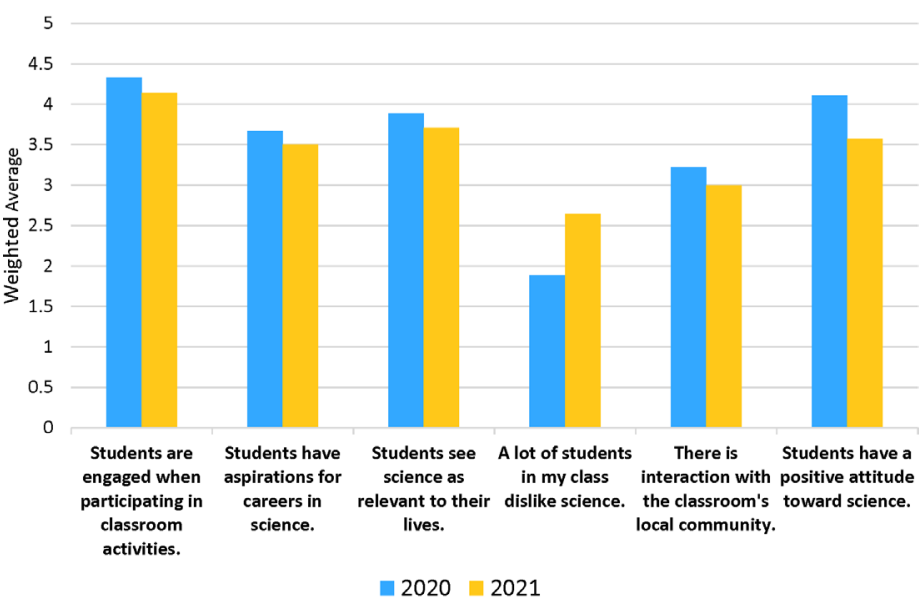

Figure 8. Teacher perception of student aspirations and attitudes at the start and the end of the COVID-19 pandemic. A higher number indicates a more positive response (i.e. $5=$ strongly agree).

It is not possible to draw firm conclusions since these responses represent the feedback of 9 teachers in 2020 and 14 teachers in 2021 and not all the same teachers may have participated in the surveys. Also, the teachers were not reporting on the same students in the two years. However, these responses suggest that, in an environment of remote learning during a pandemic, students' engagement with science diminished to some extent. We do not see this as a reflection of the program, but because of students not being able to engage directly, hands-on, with science. We will see whether that turns around during the next school year. We find it encouraging that student aspirations and attitudes about science did not plummet during the pandemic. One might have anticipated a larger drop in aspirations and change in attitude in such a challenging pandemic year, with disruption of school schedules and worry about health and well-being, but all responses remained on the positive side of neutral, in particular with regard to engagement of students in classroom activities.

\section{DISCUSSION}

There were multiple lessons learned when implementing a school-based citizen science project during a pandemic. We recognized from conversations with teachers early in the pandemic that we would need a variety of approaches to help teachers and students achieve project goals. There was no one overarching solution to the challenges posed by working with students in a remote environment during a world-wide crisis that had negative impacts on public health, local and regional economies, family food and housing security, and more. It was fortunate that we had the DataLit Institute on the calendar for June of 2020. By transitioning to a virtual training experience, we were able to shore up teacher and scientist partner relationships and provide opportunities for teachers to brainstorm and work together on solutions. 
During the institute, teachers came up with some great ideas. These included meeting more often with project coordinators and scientist partners than they had in the past, to carry the experience of working together forward into the next school year. They knew that they would be challenged to share their results with communities just as they had been in the spring of 2020. They suggested getting their students together to share findings among schools in the format of "minisymposia". Teachers knew that strengthening relationships in the "All About Arsenic" community would help to lessen the isolating effects of working remotely during a pandemic. All of these activities and efforts have set the stage for moving forward with this project. Every adaptation or intervention in the program will be maintained even as schools begin to open up and we transition back to in-person learning in our schools.

Remaining Challenges and Next Steps. The "All About Arsenic" program provides many different options for teachers and it can be challenging for them to decide what to prioritize and to avoid becoming overwhelmed. There are many ways the data can be utilized, and the complexity of the well water dataset increases with each passing year. Time management, whether in remote, hybrid, or in-person learning environments, is a continuing challenge in this project, and some teachers have expressed the worry that they are not meeting programmatic goals by not exploring every option or resource available to them. We note from teachers' quarterly reports that, even in a non-pandemic year, they are not always able to implement everything they plan at the start of the school year. Some of our project adaptations not only helped teachers to successfully engage their students in the "All About Arsenic" project during the pandemic, but will help to address these challenges in the future. In particular: 1. The independent curriculum planning tool will be modified to help teachers target those aspects of the programs that most meet their curriculum needs and goals. 2. We will continue to refine the data literacy modules to help teachers focus on essential skills. 3. We have begun to break down the well water dataset into smaller manageable pieces for teachers so that they do not need to take it all on at once. The pandemic has taught us to slow down and do what is possible, focusing on what is most important. The improved relationships among teachers and between teachers and their scientist partners, made possible through more frequent online meetings, is a valuable outcome that should help teachers meet challenges now and in the future.

\section{AUTHOR INFORMATION \\ Corresponding Author}

Jane Disney, Ph.D. MDI Biological Laboratory. PO Box 35, Salisbury Cove, ME, 04672. (207) 288-9880, Ext. 125. jdisney@mdibl.org

\section{Author Contributions}

The manuscript was written through contributions of all authors. All authors have given approval to the final version of the manuscript.

\section{ACKNOWLEDGMENTS}

We appreciate the creation of the StoryMap and mapping expertise of Gabriela Moroz and Benjamin Capuano, College of the Atlantic, contribution to the "Data to Action" toolkit development by Cameron Christopher Dunn, and program support by Bruce Stanton, Dartmouth Geisel School of Medicine. We also appreciate Molly Schauffler, Tuva consultant, Abby Roche, University of Maine graduate student in Science Communication, Sergio Cahueque, community organizer from Defend Our Health, Chris Smith, internal evaluator on the SEPA project, and teachers, students, and scientist partners who contributed to a successful project in a pandemic year.

\section{FUNDING SOURCES}

This work was supported by US EPA NE-83592001, Science Education Partnership Award (SEPA) R25GM129796-0 from the National Institute of General Medical Sciences (NIGMS) of the National Institutes of Health (NIH), NIGMS SEPA Supplement 3R25GM12979602S1, Cancer Center Support Grant P30CA023108 from the National Cancer Institute, a Prouty Pilot Grant from Friends of the Norris Cotton Cancer Center, award P42ES007373 from the National Institute Of Environmental Health Sciences of the NIH, Centers for Disease Control and Prevention (CDC) Environmental Health Capacity grant 1 NUE1EH001428-01-00, and Institutional Development Award (IDeA) Network of Biomedical Research Excellence (INBRE) grants from the NIGMS of the NIH under grant numbers P20GM103423 (Maine) and P20GM103506 (New Hampshire).. The content is solely the responsibility of the authors and does not necessarily represent the official views of the federal funding agencies or funders.

\section{ABBREVIATIONS}

CDC: Centers for Disease Control and Prevention; EPA: Environmental Protection Agency; IDeA: Institutional Development Award; INBRE: IDeA Network of Biomedical Research Excellence; MCL: Maximum Contaminant Level; MSWC: Maine Sustainability and Water Conference; NIGMS: National Institute of General Medical Sciences; SEPA: Science Education Partnership Award; STEM: Science, Technology, Engineering and Math; UbD: Understanding by Design 


\section{REFERENCES}

All About Arsenic (2021). [accessed 06/10/2021] All About Arsenic StoryMap, allaboutarsenic.org/

Baris, D., Waddell, R., Beane Freeman, L. E., Schwenn, M., Colt, J. S., Ayotte, J. D., Ward, M.H., Nuckols, J., Schned, A., Jackson, B., Clerkin, C., Rothman, N., Moore, L. E., Taylor, A., Robinson, G., Hosain, G. M., Armenti, K. R., McCoy, R., Samanic, C., Hoover, R. N., Fraumeni, J. F. Jr., Johnson, A., Karagas, M. R., and Silverman, D. T. (2016). Elevated bladder cancer in Northern New England: The role of drinking water and arsenic. JNCI: Journal of the National Cancer Institute, 108(9). PMID: 27140955

Branchaw, J.L., Butz, A.R., and Smith, A.R. (2020). Evaluation of Entering Research: A customizable curriculum for undergraduate and graduate research training programs and courses. Life Sciences Education,19(1), DOI:10.1187/ cbe.19-04-0073

Carlin, D. J, Naujokas, M. F., Bradham, K. D., Cowden, J., Heacock, M., Henry, H. F., Lee, J. S., Thomas, D. J., Thompson, C., Tokar, E. J., Waalkes, M. P., Birnbaum, L. S., and Suk, W. A. (2016). Arsenic and environmental health: State of the science and future research opportunities. Environmental Health Perspectives, 124(7), 890-899. PMCID: PMC4

Cash, D. W., Clark, W. C., Alcock, F., Dickson, N. M., Eckley, N., Guston, D. H., Jager, J., and Mitchell, R. B. (2003). Knowledge systems for sustainable development. Proceedings of the National Academy of Sciences, 100(14), 8086-8091.

D'Alessio, M., Rushing, G., and Gray, T. L. (2021). Monitoring water quality through citizen science while teaching STEM undergraduate courses during a global pandemic. Science of the Total Environment, 779, 146547. https:// doi.org/10.1016/j.scitotenv.2021.146547

Dickinson, S., and Telford, A. (2020). The visualities of digital story mapping: Teaching the 'messiness' of qualitative methods through story mapping technologies, Journal of Geography in Higher Education, 44(3), 441-457. DOI: $10.1080 / 03098265.2020 .1712686$

Erwin, R.W., Jr. (2015). Data Literacy: Real-World Learning Through Problem-Solving With Data Sets. American Secondary Education, 43(2), 18-26 Published By: Dwight Schar College of Education, Ashland University, Ashland, Ohio

Farzan, S.F., Karagas, M.R., and Chen, Y. (2013). In utero and early life arsenic exposure in relation to long-term health and disease. Toxicology and Applied Pharmacology, 272(2), 384-390. DOI: 10.1016/j.taap.2013.06.030

Gebre, E.H. (2018). Young adults' understanding and use of data: Insights for fostering secondary school students' data literacy. Canadian Journal of Science, Mathematics, and Technology Education, 18, 330-341. https://doi.org/10.1007/ s42330-018-0034-z37867
Hasni, A., Bousadra, F., Belletête, V., Benabdallah, A., Nicole, M.-C., and Dumais, N. (2016). Trends in research on project-based science and technology teaching and learning at K-12 levels: A systematic review. Studies in Science Education, 52(2), 199-231. https://doi.org/10.1080/0305726 7.2016 .1226573

Howland, M., Liss, B., Levy, T., and Najjar, M. (2020). Integrating digital datasets into public engagement through ArcGIS StoryMaps. Advances in Archaeological Practice, 8(4), 351-360. doi:10.1017/aap.2020.14

Hughes, M.F., Beck, B.D., Chen, Y., and Lewis, A.S. (2011). Thomas, DJ. Arsenic Exposure and Toxicology: A Historical Perspective. Toxicol Sci., 123(2), 305-332. doi: 10.1093/toxsci/kfr184. PMCID: PMC3179678 PMID: 21750349

Johnson, T.D., Belitz, K., and Lombard, M.A. (2019). Estimating domestic well locations and populations served in the contiguous U.S. for years 2000 and 2010. Science of the Total Environment, 687, 1261-1273. https://doi.org/10.1016/j. scitotenv.2019.06.036. PMID: 31412460.

Lee, D-M. (2020). Cultivating preservice geography teachers' awareness of geography using StoryMaps. Journal of Geography in Higher Education 44(3), 387-405. DOI: 10.1080/03098265.2019.1700487

McGreavy, B., Hutchins, K., Smith, H., Lindenfeld, L., and Silka, L. (2013). Addressing the complexities of boundary work in sustainability science through communication. Sustainability, 5(10), 4195-4221.

Malkowski, J.A., and Klenke, C.M. (2020). Rhetorical cartographic story maps as public work. Review of Communication, 20(2), 178-187, DOI: 10.1080/15358593.2020.1737201

Naujokas, M. F., Anderson, B., Ahsan, H., Aposhian, H.V., Graziano, J.H., and Suk, W.A. (2013). The broad scope of health effects from chronic arsenic exposure: update on a worldwide public health problem. Environmental Health Perspectives, 121(3), 295-302. PMID: 23458756

New Hampshire Department of Health and Human Services. Private Wells in New Hampshire: What kind do you have? [accessed 06/10/2021]. Available from: https://www.dhhs. nh.gov/dphs/lab/documents/fs-well.pdf

Nielsen, M.G., Lombard, P.J., and Schalk, L.F. (2010) Assessment of arsenic concentrations in domestic well water, by town, in Maine, 2005-09: U.S. Geological Survey Scientific Investigations Report 2010-5199 68p. (Also available at http://pubs.usgs.gov/sir/2010/5199.)

Ramirez-Andreotta, M.D., Brusseau M.L., Artiola, J..F, Maier R.M., and Gandolfi A.J. (2015). Building a co-created citizen science program with gardeners neighboring a superfund site: The Gardenroots case study. International Public Health Journal, 7(1), 139-153. PMID: 25954473. 
San Llorente Capdevila, A., Kokimova, A., Sinha Ray, S., Avellán, T., Kim, J., and Kirschke, S. (2020). Success factors for citizen science projects in water quality monitoring. Science of the Total Environment, 728, 137843. https://doi. org/10.1016/j.scitotenv.2020.137843

Shi, X., Ayotte, J.D., Onda, A., Miller, S., Rees, J., Gilbert-Diamond, D., Onega, T., Gui, J., Karagas, M., and Moeschler, J. (2015). Geospatial association between adverse birth outcomes and arsenic in groundwater in New Hampshire, USA. Environmental Geochemistry and Health, 37(2),333-51. PMID: 25326895

Wasserman, G. A., Liu, X., Lolacono, N. J., Kline, J., Factor-Litvak, P., van Geen, A., Mey, J.L., Levy, D., Abramson, R., Schwartz, A., and Graziano, J.H. (2014). A cross-sectional study of well water arsenic and child IQ in Maine schoolchildren. Environmental Health, 13(1), 23. PMID: 24684736

Wiggins, G.P., and McTighe J. (2005). Understanding by Design. 2nd ed. Upper Saddle River, NJ: Pearson.

Zieffler, A., and Fry, E. (Eds.) 2015. Reasoning About Uncertainty: Learning and Teaching In-formal Inferential Reasoning (SRTL-8). Catalyst Press. 